\title{
Application of High-Resolution Ultrasound on Diagnosing Diabetic Peripheral Neuropathy
}

This article was published in the following Dove Press journal:

Diabetes, Metabolic Syndrome and Obesity: Targets and Therapy

\author{
Hailun Huang \\ Shan Wu \\ Department of Neurology, Affiliated \\ Hospital of Guizhou Medical University, \\ Guiyang, Guizhou 55000I, People's \\ Republic of China
}

\begin{abstract}
Diabetic peripheral neuropathy (DPN) is a common complication of diabetes mellitus (DM). The typical manifestation is a length-dependent "glove and sock" sensation. At present, diagnosis is mainly dependent on clinical manifestations. Since the pathogenesis is not clear, there are no effective treatment measures. Management consists mainly of glucose control, peripheral nerve nutrition, and other measures to delay the progress of the disease; early diagnosis is therefore crucial to improving prognosis and quality of life for patients with DPN. Due to the lack of obvious symptoms in $50 \%$ of patients and the low sensitivity of neuro-electrophysiology to small fibers, the missed diagnosis rate is high. Highresolution ultrasound (HRU), as a convenient noninvasive tool, has been proven by many studies to have excellent clinical value in diagnosing DPN. With the development of related new technology, HRU shows promise for the screening, diagnosing, and follow-up of DPN, which could serve as a biomarker and provide new diagnostic insights. In this paper, we review the ability of HRU to detect nerve cross-sectional area and blood flow, and echo and other image changes, and in showing the characteristics of peripheral nerve morphological changes in patients with DPN. We also explore the application of two other recent technological developments - shear wave elastography (SWE) and ultrasound scoring systems - in improving the diagnostic efficiency of HRU in peripheral neuropathy.
\end{abstract}

Keywords: diabetes, diabetic peripheral neuropathy, high-resolution ultrasound diagnosis, muscle ultrasound

\section{Introduction}

High-resolution ultrasound (HRU), which is characterized by high resolution and large attenuation, is able to dynamically scan and continuously observe in real time the morphological changes of tissues. Typically, a conventional ultrasonic transducer uses a frequency range of 5 to $12 \mathrm{MHz}$; however, it has a high resolution that generates a frequency of $70 \mathrm{MHz}$. This more accurately displays structure, increasing the structural resolution ratio to $30 \mu \mathrm{M} .{ }^{1}$ The normal anatomic appearance of peripheral nerves was identified by ultrasound as early as 1988 by Fornage et $\mathrm{al}^{2}$. On an ultrasound image, normal nerves have an obvious architecture consisting of fascicles and a surrounding epineurium. On the transverse axis, the (lower echo) nerve bundles are surrounded by the (higher echo) nerve bundle membrane and the outer membrane to form a honeycomb structure. The nerves are slender and are parallel to the linear structure formed by the interval between the high and low echo lines on the longitudinal axis. ${ }^{3}$ ImageJ software, in conjunction with HRU, has been used to quantify changes in image echoes. ${ }^{4}$ Compared to neuro-electrophysiology, ultrasound not only has improved value and efficiency for diagnosing peripheral
Department of Neurology, Affiliated Hospital of Guizhou Medical University, Guizhou 55000I, People's Republic of China

Tel +86 I33I223I575

Email wuwushan@163.com
Diabetes, Metabolic Syndrome and Obesity: Targets and Therapy 2021:14 139-152 
neuropathy, but helps distinguish the type of neuropathy based on morphological and structural changes. ${ }^{5}$ It also plays an important role in the treatment and monitoring of peripheral neuropathy (Figures 1-3) ${ }^{5,6}$
Diabetic peripheral neuropathy (DPN) is a common complication of diabetes mellitus (DM) that is lengthdependent. It mainly involves small fiber nerves and results in symmetrical paresthesia or sensory loss and

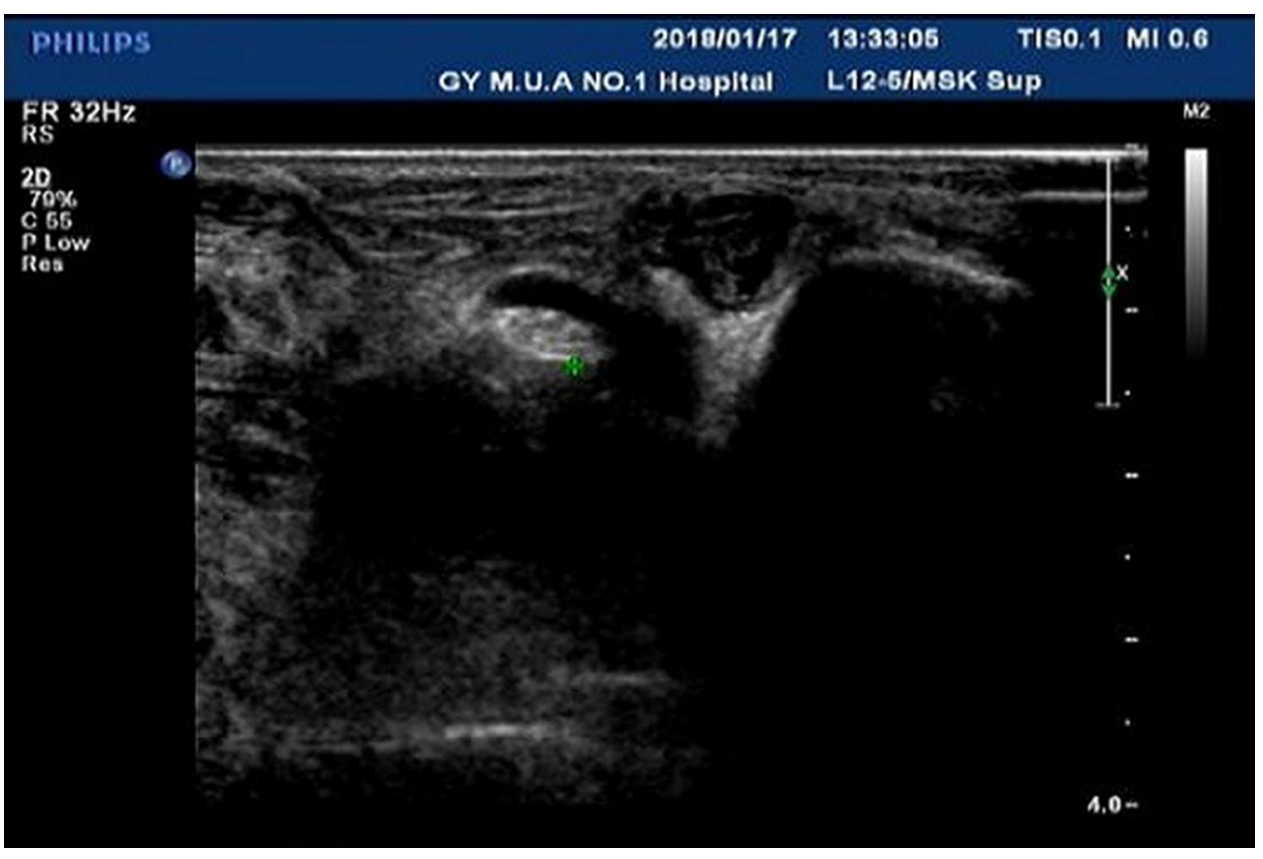

Figure I The right posterior tibial nerve of normal people shows "honeycomb" in cross section.

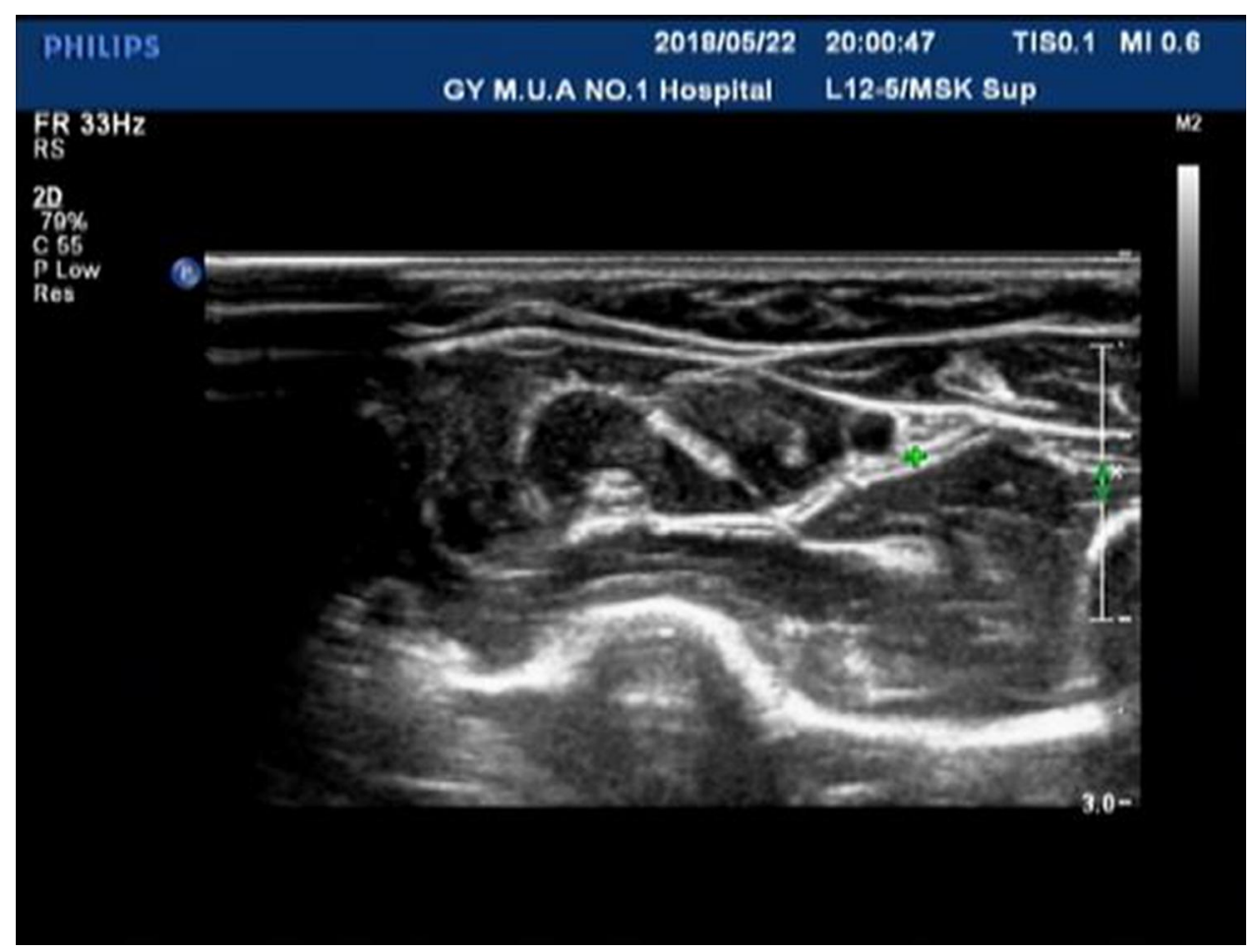

Figure 2 The right ulnar nerve (under forearm) of normal people shows "honeycomb" in cross section. 


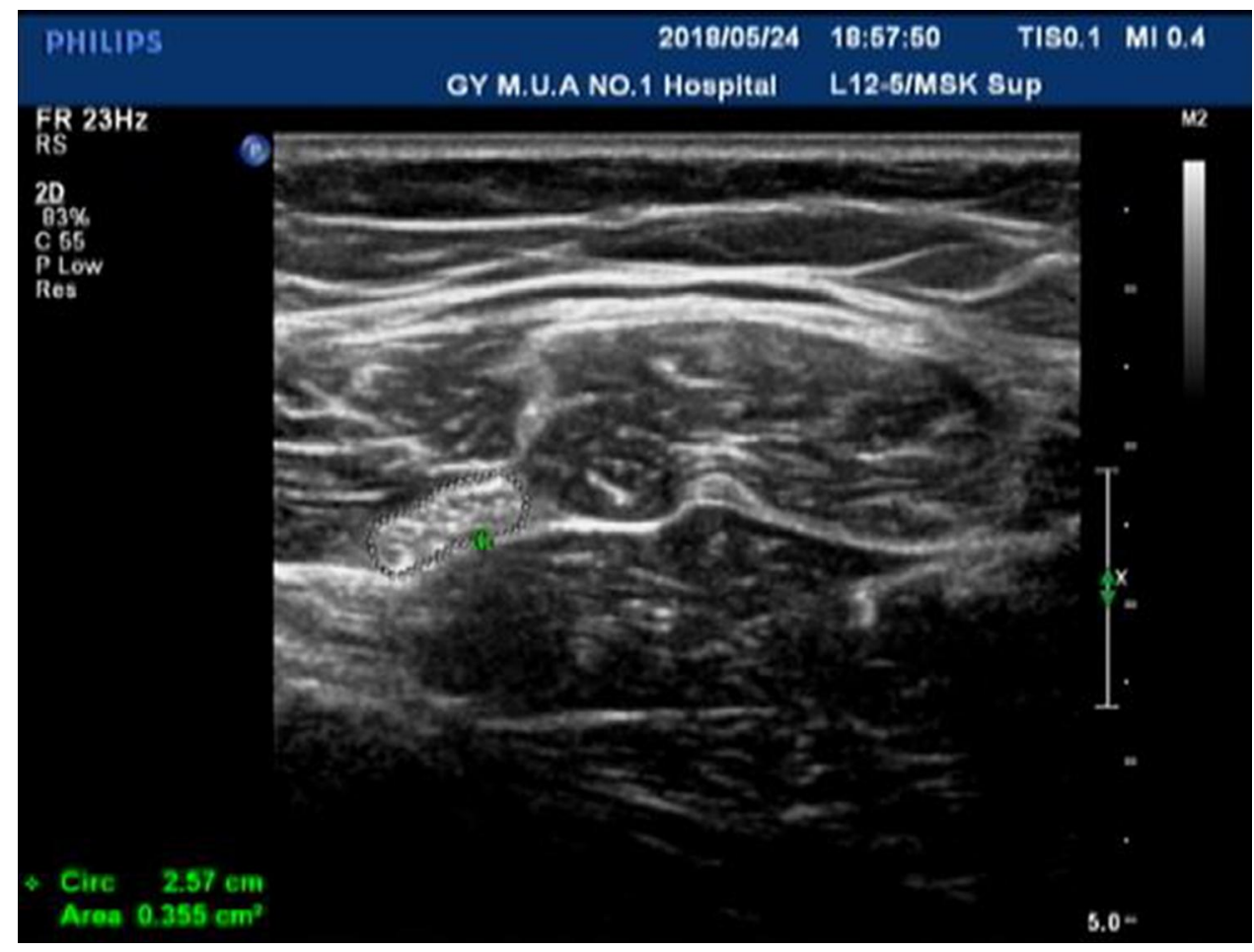

Figure 3 The left sciatic nerve (inferior margin of gluteus maximus) of normal people shows" honeycomb" on the transverse axis.

pain hypersensitivity in the early stages. The global prevalence of diabetes was reported to be nearly 500 million in 2019 , and this figure is predicted to increase by $51 \%$ by $2045 .^{7} \mathrm{DM}$ has a reported prevalence of about $50 \% ;{ }^{8} 30 \%$ of patients show neuralgia, and up to $50 \%$ of DPNs may be asymptomatic. Advanced DPN can cause serious complications, such as diabetic foot ulcers, gangrene, and subsequent amputation, which reduce the quality of life of diabetic patients. The pathogenesis is uncertain, but optimizing glycemic control early in the course of diabetes has been shown to effectively delay or prevent the development of neuropathy in type 1 diabetes. ${ }^{9}$ However, some studies have demonstrated a modest slowing of progression without reversal of neuronal loss in patients with type 2 diabetes. ${ }^{10,11}$ It is therefore important to screen for and diagnose DPN early. All patients diagnosed with type 2 diabetes should be screened for acral peripheral neuropathy once a year; patients diagnosed with type 1 diabetes should be screened every five years. ${ }^{12}$ As well as obtaining a detailed history, the screening should also evaluate the temperature sense and acupuncture sense of the small fiber system, and evaluate the large fiber system (ie, vibration sense) with a $128 \mathrm{~Hz}$ tuning fork. ${ }^{13}$ All patients should be tested with a $10 \mathrm{~g}$ monofilament once a year to determine the risk of leg ulceration or amputation. ${ }^{13}$ Intraepidermal nerve fiber density testing in skin biopsy can accurately quantify nerve fiber damage, but this is an invasive procedure and is unpopular in clinical practice. ${ }^{13}$ At present, the diagnosis of DPN is based primarily on characteristic symptoms and signs. Traditionally, nerve conduction studies (NCSs) have been the gold standard for the diagnosis of DPN; however, these are limited to assessing large nerve fibers, whereas small nerve fibers are typically the first to be affected in DPN. Only when the clinical manifestations are atypical or the diagnosis is not clear should electrophysiology be applied. ${ }^{14}$ It has become clear from recent research findings that HRU has unique diagnostic advantages in early and subclinical neuropathy.

In this review, we will focus on the application of HRU, quantitative scoring systems, and shear wave elastography (SWE) in the diagnosis of DPN and diabetic muscular atrophy, and the relationship between function and morphology in diagnosis. We will also discuss the disadvantages of these methods and possible future development directions. 


\section{Diagnostic Capability of High-Resolution Ultrasound in Diabetic Peripheral Neuropathy}

In China, the HRU measurement method refers to the standard operation of neuro-ultrasound. ${ }^{15}$ As a supplement to NCSs, HRU displays the morphology of nerve tissues by measuring nerve size, vascularity, echogenicity, and mobility. This improves the efficiency of DPN diagnosis and reduces the rates of missed diagnosis and misdiagnosis. ${ }^{16,17}$

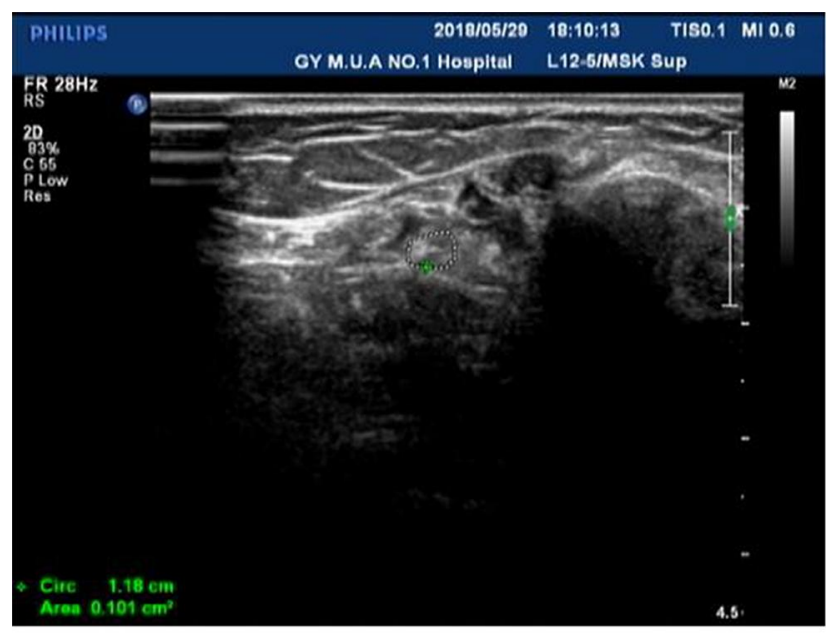

A

\section{Cross-Sectional Area of Nerve}

Image of nerves in diabetic patients are characterized by the cross-sectional area (CSA) of nerve enlargement and blurring in which the "honeycomb structure" disappears; in addition, the nerve diameter is also enlarged in the longitudinal plane and the transverse plane (Figure 4). It has also been observed that the echogenicity and boundary fuzziness of nerves in diabetic patients are significantly increased compared with controls (Figure 5). ${ }^{18}$ Entrapment is relatively specific to the osseous tunnel in diabetic patients, where abnormal

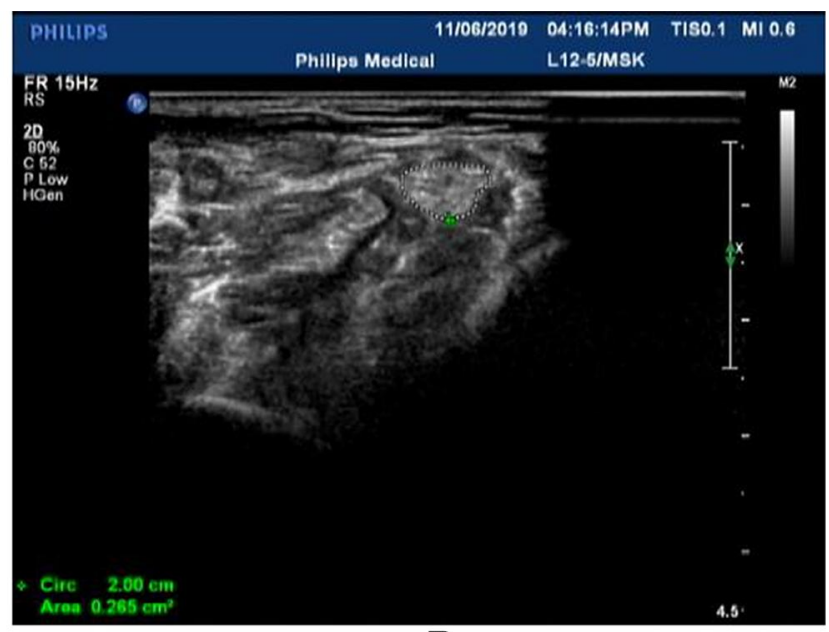

B

Figure 4 (A) The right posterior tibial nerve (white circle) in the malleolus medialis of normal people shows " honeycomb" in cross section. (B) The right posterior tibial nerve (white circle) in the malleolus medialis of patients with DPN. The development was blurred and the cross-sectional area of the nerve was significantly larger than the normal nerve with "honeycomb" disappeared.

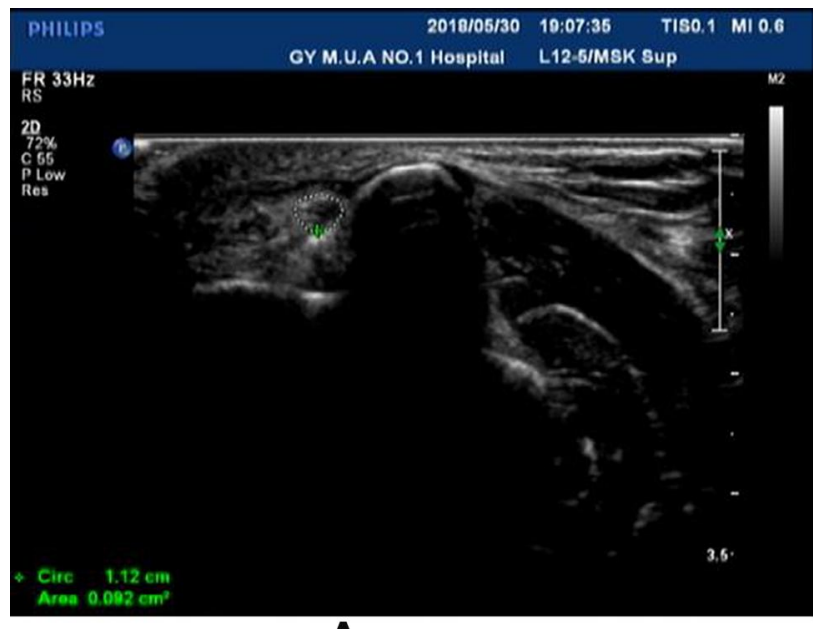

A

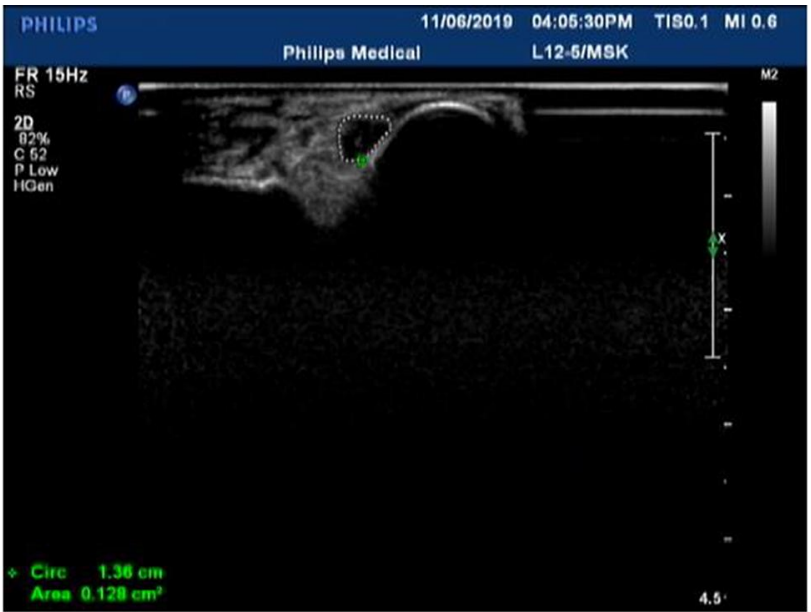

B

Figure 5 (A) The right ulnar nerve (in the carpal canal) of normal people shows " honeycomb" in cross section. (B) The echo in the carpal canal of the right ulnar nerve was significantly lower than that of the normal nerve besides enlarged cross-sectional area. 
sonographic findings are associated with compressive neuropathy and include enlargement of the proximal nerve to the site of compression and obvious attenuation at the site of compression. ${ }^{19}$ The pathogenesis is thought to involve an increase in circulating inflammatory cytokines elicited by the end products of the glycation process, resulting in demyelination and axonal loss of the peripheral nerves. ${ }^{20}$

\section{Diagnostic Value of Ultrasonography versus Electrodiagnosis in Diabetic Peripheral Neuropathy}

There is some controversy surrounding the diagnostic value of ultrasound and electrophysiology in peripheral neuropathy. On the one hand, because of the high consistency between ultrasound and NCSs, electronic diagnostic equipment is seen to be feasible as an alternative tool for clinicians. ${ }^{21}$ It has been shown that ultrasound can detect the subclinical involvement of peripheral nerves and abnormalities in patients with normal electrodiagnostic results. ${ }^{22}$ However, it has also been demonstrated that NCSs are more sensitive than ultrasound in determining the severity of ulnar neuropathy, particularly in mild or moderate neuropathy. ${ }^{23,24}$ The CSAs of the nerves of DM patients increase as the severity of DPN progresses. Research has found that, in diabetic patients, the CSA, hypoechoic area, and maximum thicknesses of the median nerve and posterior tibial nerve bundle are closely related to the degree of neuropathy $(\mathrm{P}<0.0001)$; the degree of this correlation has been shown to be significantly higher than in control subjects $(\mathrm{P}<0.05){ }^{25,26}$ Such findings are not in accordance with the findings of Singh et al: that only the average CSA of the ulnar nerve in all the tested nerves conformed to this rule. ${ }^{27}$ However, this research had several limitations - in particular, the limb nerves were measured only unilaterally. Furthermore, a correlation between ultrasound and electrophysiology was not found and the evaluation of their respective sensitivity to neuropathy severity was therefore not advanced. ${ }^{21}$ Further research is needed to determine the relationship between ultrasound and electrophysiology.

Diabetes mellitus has been reported to be a significant risk factor for carpal tunnel syndrome ${ }^{28}$ and is theoretically capable of significantly worsening this syndrome, leading to median nerve enlargement; however, study findings are conflicting. For example, when the median nerve is compressed in the carpal tunnel, the degree of nerve swelling is mainly determined by the factors related to compression, rather than the systemic effect caused by diabetes. In addition, nerve damage is affected by various factors, such as the severity and course of diabetes. Therefore, the CSA of the median nerve does not necessarily increase significantly in patients with diabetic polyneuropathy. ${ }^{29}$

\section{Relationship Between Nerve Cross-Sectional Area and Electrophysiology}

Despite advancements in science and technology, the exact relationship between dysfunction and morphological changes in diabetic polyneuropathy has not been determined. The reduced function of the $\mathrm{Na}+/ \mathrm{K}+$ pump leads to the retention of $\mathrm{Na}+$ in intracellular fluid, resulting in nerve swelling and demyelination. In one study, the pathogenesis was confirmed in type 1 diabetes patients in whom structural abnormalities of peripheral nerves were associated with markers of axonal membrane function; however, the relationship was not noted in the type 2 diabetes group - this may have been due to a metabolic mechanism. ${ }^{30}$ These metabolic processes ultimately lead to mitochondrion-mediated neuronal apoptosis, inducing downstream inflammation, oxidative stress, and molecular modifications. ${ }^{31}$ Similarly, electrodiagnostic and ultrasonographic findings have clear relevance in ulnar neuropathy at the elbow (UNE). ${ }^{32}$ However, Yan et al's results are contradictory, finding no association between dysfunction and CSA in patients with DPN (Table 1). ${ }^{33,34}$

Extant studies do not pinpoint a correlation between axonal function and structural abnormalities in peripheral nerves of diabetes patients, focusing on CSAs of nerves in patients with DM rather than comprehensive characteristics revealed by sonography.

\section{Nerve Blood Flow in Diabetes Mellitus}

It has been reported that blood flow can be observed in the nerves of DM patients by using an ultrasonic doppler (Figure 6) (similar findings have been observed for other diseases). ${ }^{35}$ An increase of intraneural blood flow may be related to the severity of disease. ${ }^{36,37}$ There may be bidirectional flow in the peripheral nerve, which ensures the supply of nutrition to the endoneurium. ${ }^{38}$ This was observed by Sun et al, who used ultrasound to compare blood flow in the nerves of patients with DPN to that in 
Table I The Relationship Between Function and Morphological Changes in DPN

\begin{tabular}{|l|l|l|l|l|l|}
\hline Author (Year of Publication) & Study Design & Patients (n) & Probe & Correlation & Functional Evaluation \\
\hline Borire AA (2018) & Cross section & 110 (type I and type 2) & $10-18 \mathrm{MHz}$ & Y in type I, but N in type 2 & QTRAC automated software \\
Podnar Simon (2017) & Cross section & $160(\mathrm{UNE})$ & $13 \mathrm{MHz}$ & $\mathrm{Y}$ & Nerve conduction studies \\
Yan A (2020) & Cross section & $57($ type 2) & $10-18 \mathrm{MHz}$ & $\mathrm{N}$ & QTRAC automated software \\
Arumugam T (2016) & Cross section & 100 (type 2) & $12 \mathrm{MHz}$ & $\mathrm{N}$ & Nerve conduction studies \\
\hline
\end{tabular}

Abbreviations: UNE, ulnar neuropathy at the elbow; Y, relevant; N, uncorrelated.

non-DPN and healthy groups. ${ }^{39}$ Similar findings have been produced elsewhere, where the phenomenon results from changes in vasodilation. Arteriosclerosis has been shown to reduce blood flow, which can help in determining the severity of DPN in patients. ${ }^{40}$ Recently, focused ultrasound (FUS) has been found to improve microcirculation and increase upstream arterial blood flow in diabetic feet, thereby slowing the progress of neuropathy. ${ }^{41}$

Some research suggests that neuropathic changes can be initiated in the early stages of diabetes pathogenesis. ${ }^{42}$ Changes have been revealed by HRU in the adventitia and internal ethmoidal structure, and in the echogenicity. At present, the morphological changes in DPN evaluated by HRU lack a unified evaluation standard. Moreover, there are still no effective methods for treating DPN, making screening and early diagnosis essential.

\section{Ultrasound as a Quantitative Tool for Diabetic Peripheral Neuropathy}

DPN, a diffuse polyneuropathy, is a complication of diabetes. HRU has shown DPN to occur in nerves in varying degrees. ${ }^{43}$ There is no unified standard for reading

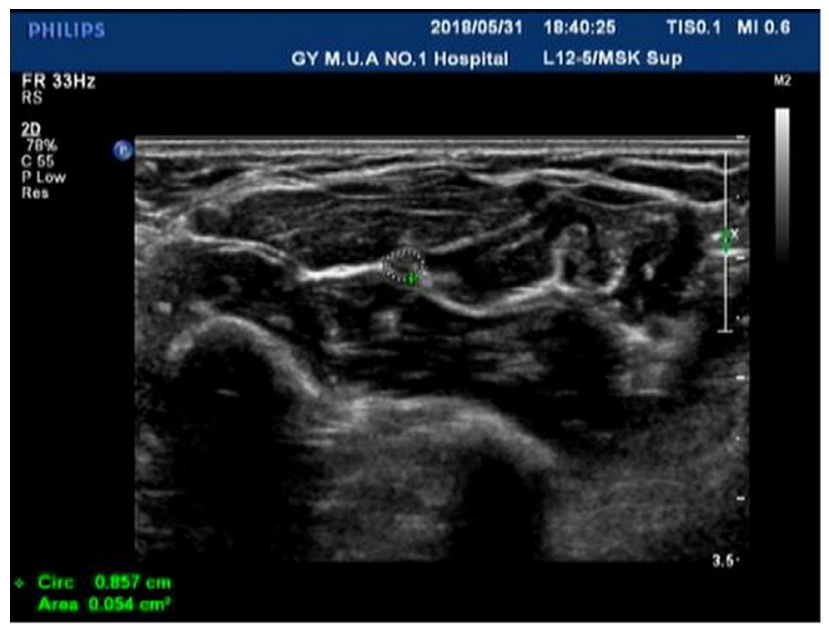

A ultrasonic images of DPN, and the results are easily affected by subjective factors during evaluation. It is therefore important that a scoring system that can thoroughly quantify ultrasonic images is devised.

\section{Ultrasonographic Scoring System Based on Cross-Sectional Area of Nerve}

Ultrasound has shown that the CSAs of nerves may increase as DPN progresses, particularly when the neurophysiology is not fully understood. Few research papers have quantified neuro-ultrasound results, but a small number of ultrasound scoring systems have been established to standardize and operationalize ultrasonic examinations. The Bochum ultrasound score (BUS) can effectively distinguish chronic and acute inflammatory demyelinating polyradiculoneuropathies (CIDP and AIDP) (sensitivity 90\%, specificity $90.4 \%$ ), ${ }^{44,45}$ and can also distinguish chronic immune-mediated neuropathies. ${ }^{46} \mathrm{~A}$ second system, the ultrasound pattern sum score (UPSS) comprising three sub-scores (UPS-A for the sensorimotor nerves, UPS-B for the cervical roots and the vagal nerve, and UPS-C for the sural nerve), has been shown

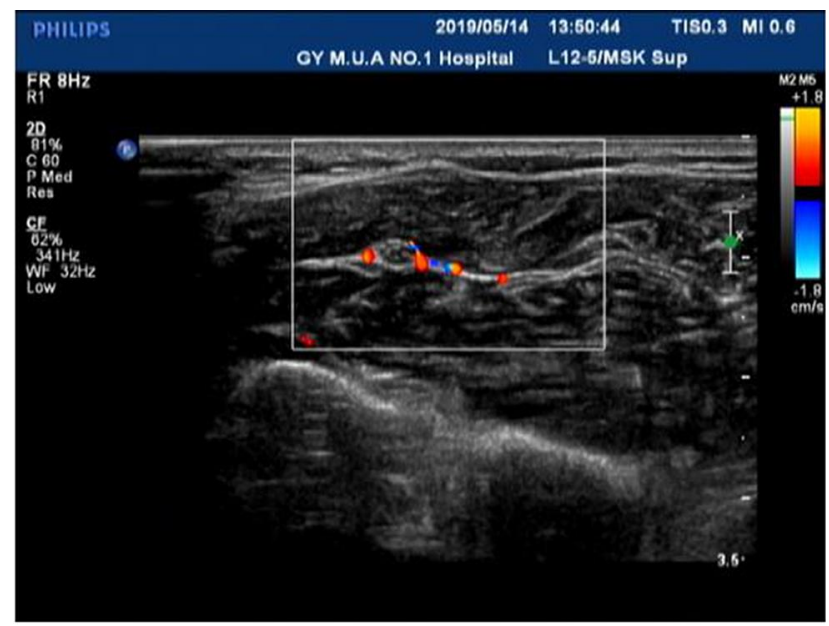

B

Figure 6 (A) Median nerve in forearm from healthy people. (B) The median nerve in the forearm of DPN patients, the blood flow signals of peripheral nerve and surrounding tissues were abundant. 
to enhance identification efficiency; studies affirm that UPS$\mathrm{A}$ and UPSS can diagnose acute and subacute-onset CIDP and its variants with the sensitivity of $80 \%$ and $78.5 \%$, respectively; specificity of $95.9 \%$ and $97.3 \%$, respectively; and positive predictive value. An increased UPS-B with normal UPSS and other sub-scores may point to a diagnosis of Guillain-Barré syndrome (GBS) with a high positive predictive value and facilitate differentiation from CIDP. ${ }^{47}$ The same method has also been used to differentiate between Charcot-Marie-Tooth hereditary neuropathy (CMT1) and CIDP, multifocal motor neuropathy (MMN), and multifocal acquired demyelinating sensory and motor neuropathies (MADSAM) ${ }^{48,49}$ which have been shown to be differentiated from each other by pattern analysis of fascicles that considers the number of visible fascicles in a cross-section. ${ }^{50}$ A novel study scoring system was created on the basis of this scoring system, with a cut-point $\geq 3$ according to sensitivity curve analysis. A sensitivity of $64 \%$ and specificity of $77 \%$ for distinguishing between DSP and non-DSP was demonstrated, in which the cut-off value for the sural nerve at $2 \mathrm{~mm}^{2}$ was a good discriminator (area under the curve $=0.88$ ) between the presence and absence of DPN (sensitivity $90 \%$, specificity $74 \%$ ) (Table 2 ). ${ }^{51}$

\section{Quantitative Diagnosis of Nerve Blood Flow}

Previous studies have reported the diagnostic value of HRU with doppler sonography in patients with peripheral neuropathy, which has been shown to correlate well with intraneural blood flow assessment and electrophysiological indices. ${ }^{52}$ In one study, ${ }^{53}$ nerves in diabetic patients were found to have higher rates of nerve blood flow (28\%) than the control group $(\mathrm{P}<0.0001)$. Significant correlations have been found between nerve blood flow measurements and nerve size $(\mathrm{P}<0.001)$, reported sensory symptoms $(\mathrm{P}<$ $0.05)$, and neuropathy severity scores $(\mathrm{P}<0.001)$; these correlations are likely attributable to the compensatory changes that occur in the epineurial vessels in response to endoneurial ischemia and hypoxia. A gradual increase in maximum perfusion intensity with worsening neuropathy severity has been observed. ${ }^{53}$ In addition, it has been demonstrated that the velocity of intraneural blood flow in carpal tunnel syndrome depends on median nerve function and wrist posture. ${ }^{54}$ Therefore, it is necessary to evaluate blood perfusion of the peripheral nerves; contrast-enhanced ultrasound was confirmed by a study using 12 normal New Zealand white rabbits as a feasible method for the quantitative evaluation of peripheral nerve perfusion. ${ }^{55}$

\section{The Value of Quantifying Echoes of Nerves in Addition to Cross-Sectional Areas}

Sonographic examinations are useful in the diagnosis of diabetic neuropathy. It has been observed that the CSAs of nerves are significantly increased in diabetic patients compared with controls, and there are also echogenic changes. One study noted a significant increase in the CSA and hypoechoic area of nerves in diabetic patients compared with controls, which was attributed to increased water content and was consistent with Huang's investigations of the sciatic nerve in diabetic rats. ${ }^{56}$ In Huang's findings on quantitative ultrasound evaluations, hyperechoic intraneural structure was observed, and the echo intensity of the sciatic nerve was found to be increased in diabetic rats at the fourth month of hyperglycemia ( $p>0.05$ ); this increase was not found in lean control rats, indicating a correlation with functional deficits and histological changes based on the severity of DPN. The reason for this could be the association with either the water content or the uniform matrix of fibrillary collagen. In the same study, the fiber density of the sciatic nerve was reduced at the fourth month of hyperglycemia. ${ }^{4}$

\section{A New Sonographic Scoring System in China}

More recently, a novel ultrasonic scoring system, the DCEC scoring system, has been established on the

Table 2 Comparison of Studies Showing the Application of Ultrasonic Scoring System in Different Peripheral Neuropathy

\begin{tabular}{|l|l|l|l|l|l|}
\hline Year & Author & Scoring System & Application & Sensitivity & Specificity \\
\hline 2014 & Kerasnoudis A & BUS & Distinguish CIDP and AIDP & $90 \%$ & $90.40 \%$ \\
2015 & Grimm A & UPSS & Distinguish acute and subacute-onset CIDP and its variants & $(80 \% ; 78.5 \%)$ & $(95.9 \% ; 97.3 \%)$ \\
2016 & Grimm A & UPSS & Differentiation between CMTI, CIDP and MMN & $81.80 \%$ & $71.90 \%$ \\
2017 & Breiner A & SSS & Distinguishing between DSP and non-DSP & $64 \%$ & $77 \%$ \\
\hline
\end{tabular}

Abbreviations: BUS, Bochum ultrasound score; CIDP, chronic inflammatory demyelinating; AIDP, acute inflammatory demyelinating; UPSS, ultrasound pattern sum score; CMTI, Charcot-Marie-Tooth hereditary neuropathy; MMN, multifocal motor neuropathy; SSS, Study Scoring System. 
basis of the UPSS sub-score UPS-A. ${ }^{47}$ It calculates the total scores, including the definition, CSA, echo, and entrapment of nerves, as the ultrasonic quantitative evaluation index. It was first proposed by $\mathrm{Wu}$ et al and applied to the evaluation of 40 patients with asymmetric pathological pain. The significant difference was found between the scores of the painful side and the contralateral limb. The diagnostic value of DCEC score for painful side and contralateral limb was therefore determined, with the sensitivity of $60.9 \%$ and $88.2 \%$, respectively, and specificity of $88.2 \%$ and $60.9 \%{ }^{16}$ Ou Yang et al claim that the DCEC scoring system can also be used to diagnose DPN. The cut-off value for peripheral nerves from the arms and legs, 14.5, is a good indicator (area under the curve 0.85 ) of the presence or absence of DPN (sensitivity $81 \%$, specificity 80\%). Studies with larger multi-center cohorts are needed to thoroughly investigate the diagnostic value of the DCEC scoring system. $^{57}$

The morphological changes shown by ultrasound are affected by a variety of factors. For example, total body adiposity and blood triglyceride levels are strong independent risk factors for DPN and have been associated with nerve CSA in DM patients, which increases with the severity of DPN. ${ }^{58-60}$ Therefore, it is necessary to quantify the ultrasonic morphology of nerves to improve the accuracy of $\mathrm{HRU}$ in diagnosing DPN. At present, most research is limited to the quantitative study of the CSAs of nerves; an overall quantitative scoring system of various ultrasound evaluation indexes remains lacking.

\section{Improving the Diagnostic Value in DPN by Shear Wave Sonoelastography}

The efficiency with which peripheral neuropathy is diagnosed has greatly improved with the development of ultrasound. Previous research has demonstrated that shear wave elastography (SWE) has potential as a tool for diagnosing ulnar tunnel syndrome, in which the CSA of the ulnar nerve at the Guyon's canal level is equal to $5 \mathrm{~mm}^{2}$ or greater; this method achieved specificity of $97.4 \%$ and sensitivity of $56.5 \%{ }^{61}$ This new technique is able to measure the stiffness/elasticity of the tissues, reflected in the elastic changes in the degree of tissue deformation after compression. ${ }^{62}$ This can aid in understanding the degree of tissue lesions, and in distinguishing benign and malignant diseases; it has proven diagnostic value in conditions affecting thyroid, breast, liver, etc. and compensates for the limitations of conventional ultrasound in the detection of tumors and other diseases. ${ }^{63,64}$

Few studies have assessed changes in the elasticity of the peripheral nerves in diabetic patients with or without diabetic neuropathy, although some studies have demonstrated that such assessment has potential for characterizing diabetic neuropathy. The value of SWE in detecting DPN of the tibial nerve in diabetic DPN patients has been shown to be higher than that of HRU. Moreover, the stiffness value of nerves has been observed to be significantly higher in diabetic patients without clinical or electrophysiologic signs of DPN than in a control group, indicating subclinical and subelectrophysiologic DPN. The SWE stiffness cut-off value for a diagnosis of DPN was $51.05 \mathrm{kPa}$ (sensitivity 90\%, specificity 85\%). However, in the diagnosis of DPN according to CSA cut-off value $\left(0.1575 \mathrm{~cm}^{2}\right)$, sensitivity and specificity were lower (60\% and $75 \%$, respectively). ${ }^{65}$ These results are similar to results noted by Ishibashi et $\mathrm{al}^{66}$. The elasticity of the tibial nerve has been shown to be negatively associated with neuropathy severity, CSA, and the $2000 \mathrm{~Hz}$ current perception threshold, and positively associated with nerve conduction velocities. The key is that, in type 2 diabetic patients, fibers in the sheaths of peripheral nerves thicken, resulting in an elastic change of the tibial nerve (Table 3 and Figure 7). ${ }^{66-68}$ Further studies are required to explore the mechanisms that underlie elastic changes in multiple peripheral nerves in DM patients at follow-up.

As SWE is able to reflect the elasticity of muscles, further investigations into the diagnostic value of SWE in diabetic

Table 3 Comparison of Diagnostic Value of Nerve Elasticity and Cross-Sectional Area in Diabetic Peripheral Neuropathy

\begin{tabular}{|c|c|c|c|c|c|}
\hline \multirow[t]{2}{*}{ Year } & \multirow[t]{2}{*}{ Author } & \multicolumn{2}{|l|}{ CSA } & \multicolumn{2}{|l|}{ SWE } \\
\hline & & Sensitivity & Specificity & Sensitivity & Specificity \\
\hline 2017 & Dikici $A S^{65}$ & $60 \%$ & $75 \%$ & $90 \%$ & $85 \%$ \\
\hline 2016 & Ishibashi $F^{66}$ & $62 \%$ & $56.80 \%$ & $86 \%$ & $69.60 \%$ \\
\hline 2020 & Chen $R^{68}$ & $93.30 \%$ & $62.10 \%$ & $73.30 \%$ & $90.90 \%$ \\
\hline
\end{tabular}

Abbreviations: CSA, cross-sectional area; SWE, shear wave elastography. 


\section{A}

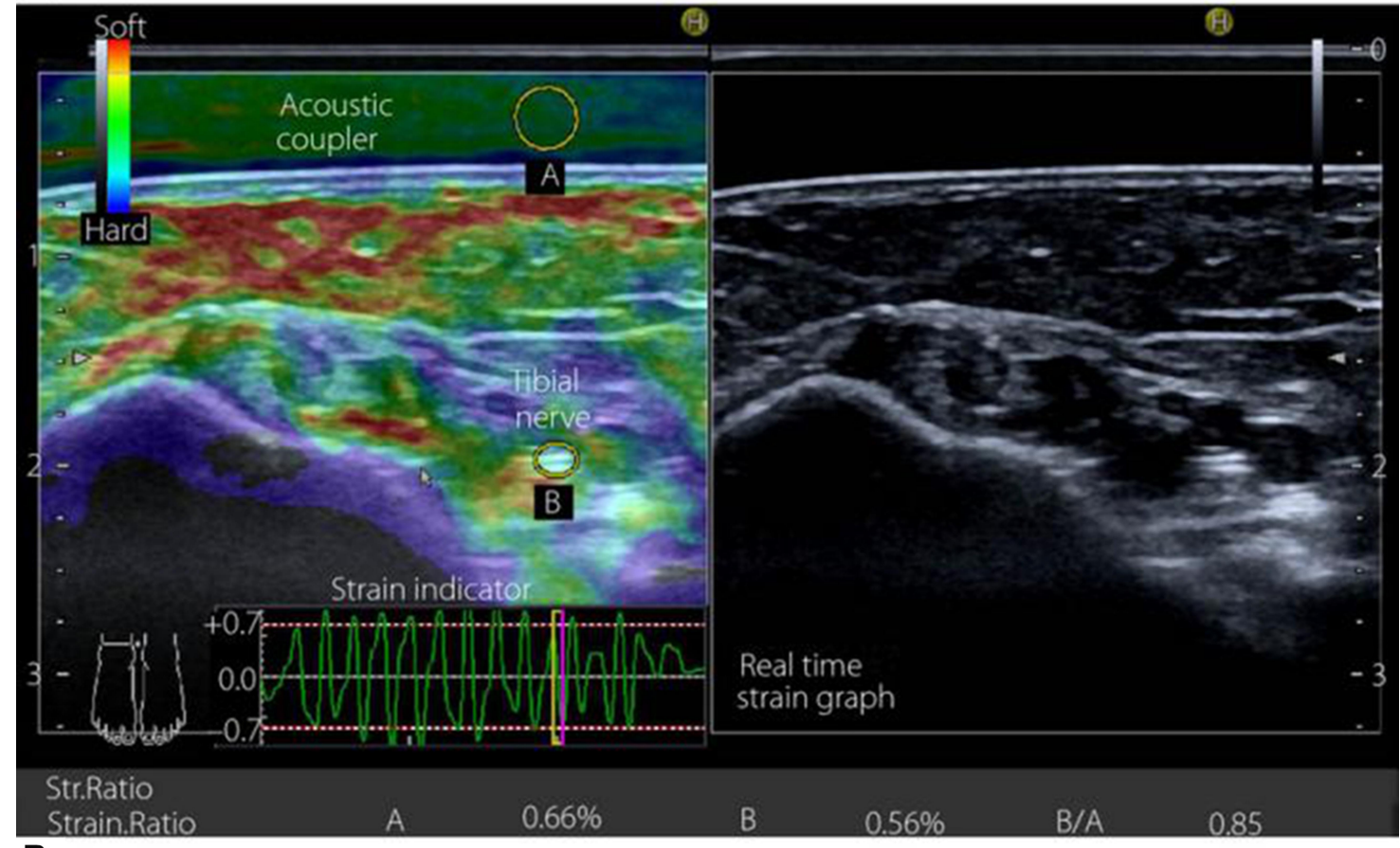

B

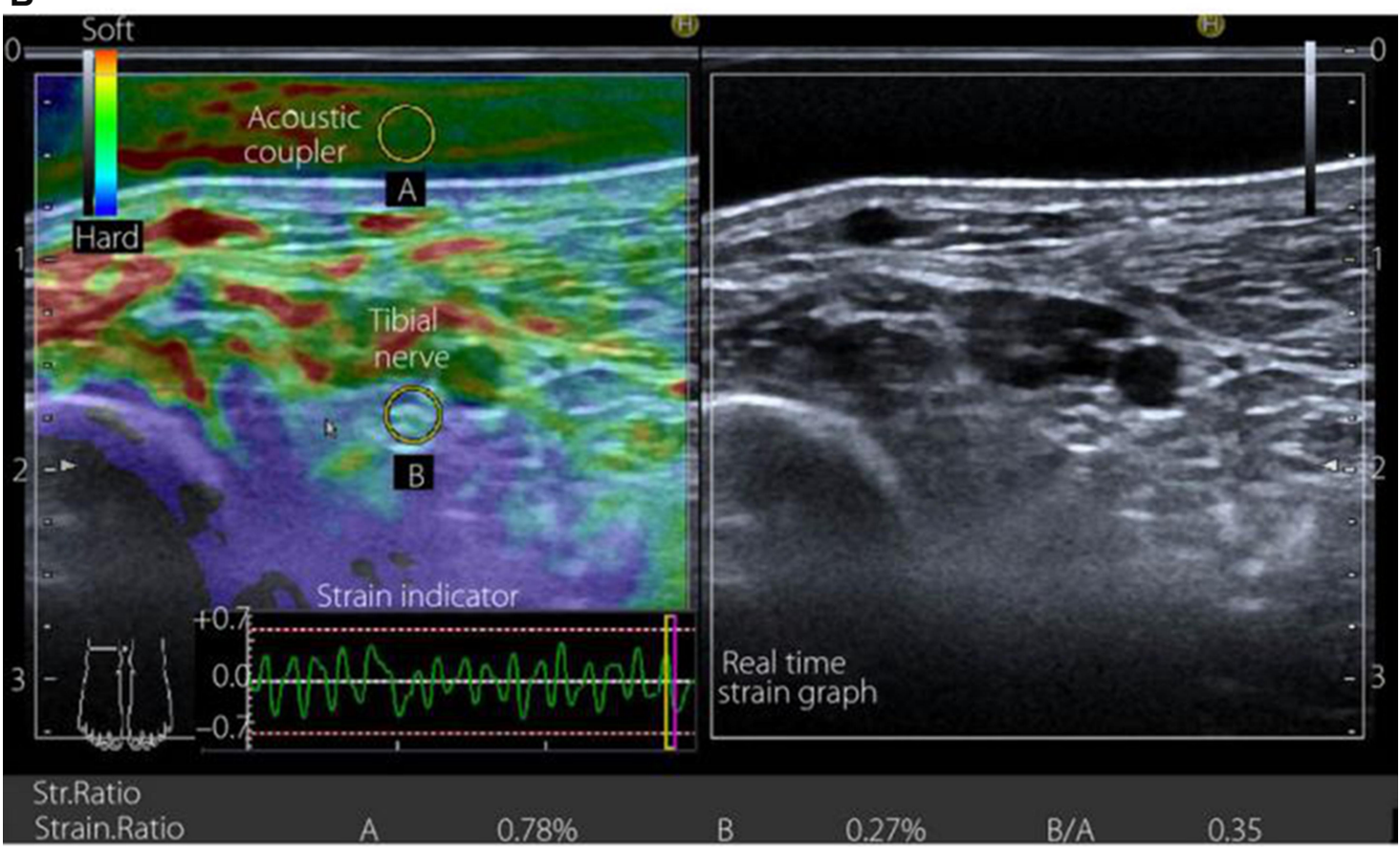

Figure 7 Transverse sectional image of the tibial nerve in (A) a 48-year-old male control participant and (B) a 52-year-old male patient with type 2 diabetes at stage III neuropathy, visualized by high-resolution ultrasonography using an I8.0-MHz linear array probe (HIVISION Ascendus; Hitachi Medical, Tokyo, Japan) attached with an acoustic coupler (EZUTECPLI; Hitachi-Aloka Medical, Tokyo, Japan). A translucent color-coded image represents the relative stiffness of tissues. Mild compression and decompression using a probe attached with an acoustic coupler were repeated on the tibial nerve. Representative sonoelastographic images were chosen from images stored as cine loops. The tibial nerve and region of the acoustic coupler located directly above the tibial nerve are shown with a circle. The elastograms were constructed automatically. The elasticity of the tibial nerve was assessed as the tibial nerve:acoustic coupler strain ratio. The measurements were repeated three times and averaged. Reproduced from Ishibashi F, Taniguchi M, Kojima R, Kawasaki A, Kosaka A, Uetake H, Elasticity of the tibial nerve assessed by sonoelastography was reduced before the development of neuropathy and further deterioration associated with the severity of neuropathy in patients with type 2 diabetes. J Diabetes Investig. 7(3):404-412. Copyright $\odot$ [20I5], John Wiley and Sons. ${ }^{66}$ 
amyotrophy would be of interest. Vibration-controlled transient elastography has been shown to be capable of accurately confirming the presence or absence of cirrhosis in many etiologies of chronic liver disease. Its measurements of liver stiffness are highly accurate compared with the reference standard of liver biopsy for diagnosing cirrhosis. However, there remains a lack of reliability in the staging diagnosis of some patients with mild liver fibrosis. ${ }^{69}$ The current standard for staging diagnosis is lacking in relation to the application of SWE in peripheral neuropathy in China and in other countries. Therefore, further studies are needed to determine criteria for staging diagnosis of DPN by SWE.

\section{Diagnosis of Diabetic Muscular Atrophy}

Diabetic amyotrophy (DA) is a rare disease secondary to diabetic neuropathy that exhibits lesions in the area dominated by the lumbosacral plexus, leading to muscle atrophy. A reduction in the diameter of the myofibers of the extensor digitorum longus and rectus femoris muscles of STZ-diabetic rats (compared with a control group) has been noted; it was attributed to the direct effect of low serum insulin on the motor end plates and on the synthesis of contractile proteins. The estimated numerical density of myonuclei per unit area was $10 \%$ lower in both muscles. ${ }^{70}$ Moreover, advanced glycation end products (AGEs) induced muscle atrophy/myogenesis impairment via a receptor for AGEs (RAGE)-mediated AMPK-downregulation of the Akt signaling pathway. ${ }^{71}$ There was atrophy of the distal muscles in the extremities in most patients; proximal involvement was seen in only a few patients. A loss of foot muscle volume was negatively related to the severity of neuropathy as assessed at clinical evaluation. ${ }^{72}$ For most patients, muscular atrophy is irreversible once it is visible to the naked eye, so detecting atrophy early in the innervated area of nerve damage is helpful in delaying the development of the disease. Prompted by the limitations of HRU and electrophysiology, some research has discovered that high-resolution magnetic resonance neurography (MRN) may have a degree of diagnostic value in DA. Magnetic resonance imaging of the distal part of the leg has shown that substantial muscular atrophy is closely related to the degree of muscle weakness. ${ }^{73,74} \mathrm{MRN}$, when used for the first time in patients with distal symmetric diabetic polyneuropathy (dPNP), revealed fascicular symmetric lesions located within the proximal nerve trunks. Multifocal fascicular symmetric intraneural T2 lesions occurred in the proximal trunks of the sciatic nerves in four patients, but not in patients in the control group, as confirmed by quantitative analysis. This supports the view that the accumulation of proximal multifocal fascicular injury could be important in disease progression. ${ }^{75}$ Similar results were noted by Hlis. Responding to the lack of quantitative systematic scientific investigation of the use of MRI or MRN in the evaluation of DA, Hlis employed MRN as a non-invasive diagnostic tool for the quantitative characterization of DA in 40 controls and 23 DA cases. ${ }^{76}$ Nevertheless, using MRI or MRN in the early diagnosis of diabetic muscular atrophy is not feasible. Other studies have investigated the application of HRU in muscle evaluation. Not only has HRU been shown to clearly display the echo, thickness, and CSA of muscles, it can also help to observe muscle damage and muscular fibrillation and to diagnose inflammatory myopathy. HRU has been shown to play an important role in the effective diagnosis and evaluation of some neuromuscular diseases and amyotrophic lateral sclerosis. ${ }^{77}$ In research by Severinsen, HRU was used to detect foot muscle volume in diabetic patients, which is helpful for the diagnosis of DA. ${ }^{78}$ Based on this method, we measured the extensor digitorum brevis and the first and second metatarsal interosseous muscles in diabetic patients by HRU (Figure 8). De Souza Silva and et al used the same method to demonstrate that ultrasound measurements of the quadriceps muscles showed high to very high intraand inter-rater reliability, thus enabling its use in monitoring muscle changes provoked by diabetes or interventions in individuals with type 2 diabetes. $^{79}$

Muscular atrophy is not uncommonly seen in clinical practice; however, its diagnosis is limited to visible muscle volume reduction, which is not readily observable in the early stages of disease. It has been reported that microvascular malfunctions of muscle tissue are affected by hyperglycemia and are correlated with the severity of diabetic neuropathy in later stages. ${ }^{80}$ With the development of HRU, muscle atrophy (resulting from a variety of factors) can be identified at an earlier stage. The lack of research on the normal value of muscle observed by ultrasound and the diagnostic value of muscle in patients with DA necessitates further study using HRU of the characteristics of various neurologic diseases.

\section{Future Prospects}

The diagnostic value of ultrasound for DPN is improved by combining it with nerve conduction examination. 


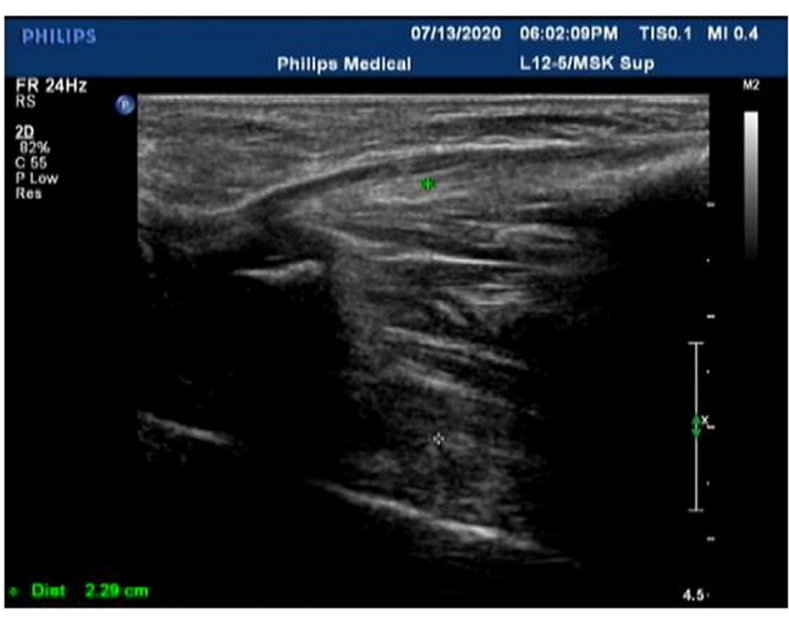

A

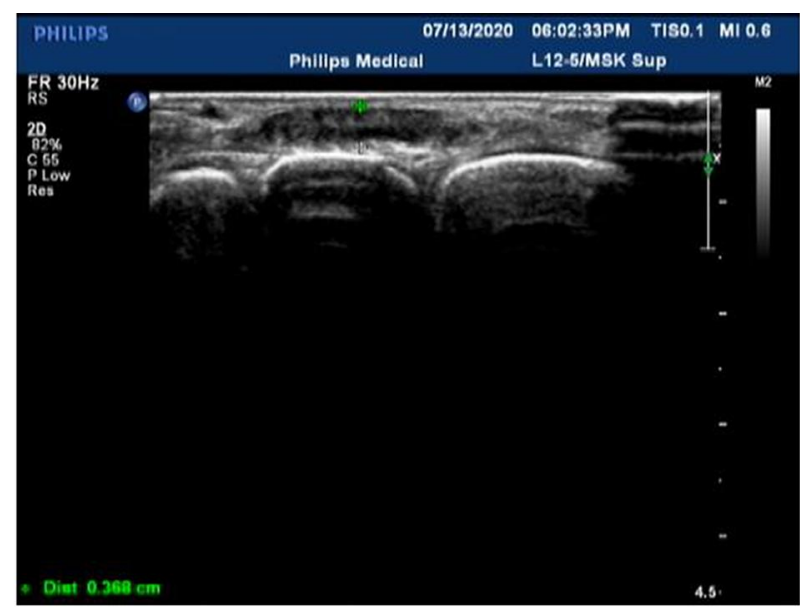

B

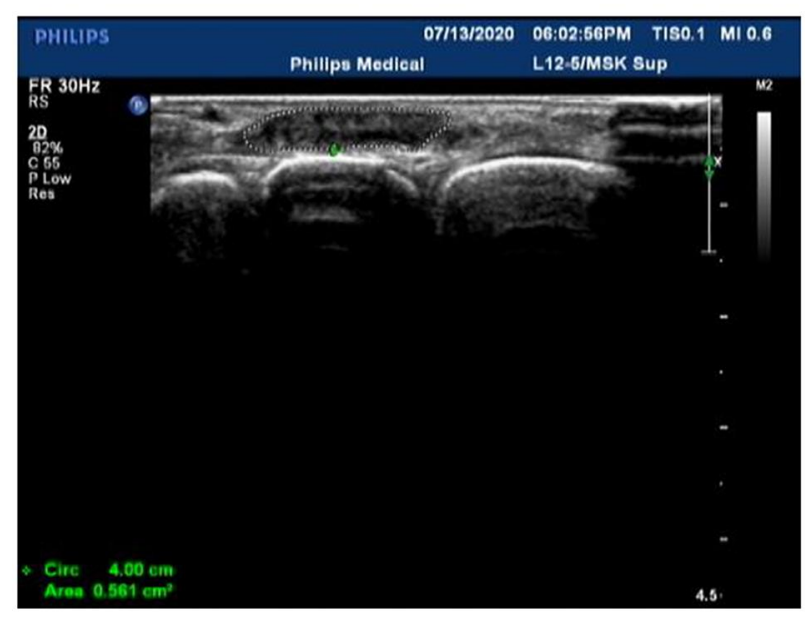

C

Figure 8 (A) Thickness of the first and second metatarsal interosseous muscles in the left dorsum of diabetic peripheral neuropathy (between green * and white *); (B) Thickness of extensor digitorum brevis of the left foot in patients with diabetic peripheral neuropathy (between green * and white *); (C) Cross-sectional area of extensor digitorum brevis of theleft foot in patients with diabetic peripheral neuropathy (white circle).

Furthermore, ultrasound can be used to detect anatomical variations and space-occupying lesions in the carpal tunnel to monitor the therapeutic response in patients with carpal tunnel syndrome and evaluate median nerve injuries. ${ }^{81}$ This offers great potential for identifying subclinical lesions and prognosis. However, there is currently a level of controversy over the correlation between the results of HRU and nerve conduction. Additionally, several studies focus on the tibial nerve of the lower extremities, which, although consistent with the characteristics of DPN length dependence, is not practical for clinical diagnosis. DPN is a multiple neuropathy according to the characteristics of ultrasound images; therefore, further studies are needed to promote the development of auxiliary diagnosis in the quantification and staging of DPN.

\section{Conclusion}

In conclusion, HRU has the advantages of being noninvasive and repeatable and is promising in the auxiliary diagnosis of DPN and its prognosis. HRU is the most direct and accurate tool available for observing nerve entrapment. Combining ultrasound and nerve conduction examination can improve the diagnostic value of this method for DPN and avoid missed diagnoses and misdiagnosis. In addition, this method helps evaluate the severity and prognosis of DPN, when fuzzy boundaries, increased CSA, and hypoechoic region are identified. However, it has certain limitations in the exploration of the deep neuromuscular and lumbosacral plexus. In light of the popularization of HRU, particularly shear wave elastic ultrasound, this technology is expected to replace neuro-electrophysiological 
examination for DPN diagnosis in the future. Research on HRU in the quantitative diagnosis and staging of DPN is currently lacking. As a non-invasive and painless method of examination, HRU has high value and broad application prospects in the clinical evaluation and prognosis of DPN patients.

\section{Acknowledgments}

We thank the staff from the Ultrasound Room of the Department of Neurology, the Affiliated Hospital of Guizhou Medical University for their help.

\section{Author Contributions}

All authors contributed to drafting or revising the article, have agreed on the journal to which the article will be submitted, gave final approval of the version to be published, and agree to be accountable for all aspects of the work.

\section{Funding}

The study was supported by the Guiyang science and technology plan project. No. [2019]9-1-7, National Key R\&D Program of China (NO.2018YFC1312901), and Science and technology projects in Guizhou Province [2015]7407. The funders had no role in study design, data collection and analysis, decision to publish, or preparation of the manuscript.

\section{Disclosure}

There are no conflicts of interest for this work.

\section{References}

1. Kessler JM, de la Lama M, Umans HR, et al. High-frequency sonography of the volar digital nerves of the hand. Muscle Nerve. 2012;45 (2):222-226. doi:10.1002/mus.22277

2. Fornage BD, Rifkin MD. Ultrasound examination of the hand and foot. Radiol Clin North Am. 1988;26(1):109-129.

3. Suk JI, Walker FO, Cartwright MS. Ultrasonography of peripheral nerves. Curr Neurol Neurosci Rep. 2013;13(2):328. doi:10.1007/ s11910-012-0328-x

4. Huang Y, Hu B, Zhu J. Study on the use of quantitative ultrasound evaluation of diabetic neuropathy in the rat sciatic nerve. Australas Phys Eng Sci Med. 2016;39(4):997-1005. doi:10.1007/s13246-0160448-8

5. Tan CY, Arumugam T, Razali SNO, Yahya MA, Goh KJ, Shahrizaila N. Nerve ultrasound can distinguish chronic inflammatory demyelinating polyneuropathy from demyelinating diabetic sensorimotor polyneuropathy. J Clin Neurosci. 2018;57:198-201. doi:10. 1016/j.jocn.2018.08.031

6. Härtig F, Ross M, Dammeier NM, et al. Nerve ultrasound predicts treatment response in chronic inflammatory demyelinating polyradiculoneuropathy-a prospective follow-up. Neurotherapeutics. 2018;15:439-451. doi:10.1007/s13311-018-0609-4
7. Saeedi P, Petersohn I, Salpea P, et al.; IDF Diabetes Atlas Committee. Global and regional diabetes prevalence estimates for 2019 and projections for 2030 and 2045: results from the International Diabetes Federation Diabetes Atlas, 9th edition. Diabetes Res Clin Pract. 2019;157:107843. doi:10.1016/j.diabres.2019.107843

8. Hicks CW, Selvin E. Epidemiology of peripheral neuropathy and lower extremity disease in diabetes. Curr Diab Rep. 2019;19:86. doi:10.1007/s11892-019-1212-8

9. Albers JW, Herman WH, Pop-Busui R, et al.; Diabetes Control and Complications Trial/Epidemiology of Diabetes Interventions and Complications Research Group. Effect of prior intensive insulin treatment during the Diabetes Control and Complications Trial (DCCT) on peripheral neuropathy in type 1 diabetes during the Epidemiology of Diabetes Interventions and Complications (EDIC) study. Diabetes Care. 2010;33:1090-1096. doi:10.2337/dc09-1941

10. Ismail-Beigi F, Craven T, Banerji MA, et al. Effect of intensive treatment of hyperglycaemia on microvascular outcomes in type 2 diabetes: an analysis of the ACCORD randomised trial. Lancet. 2010;376:419-430. doi:10.1016/S0140-6736(10)60576-4

11. Callaghan BC, Little AA, Feldman EL, Hughes RA. Enhanced glucose control for preventing and treating diabetic neuropathy. Cochrane Database Syst Rev. 2012;6:CD007543.

12. Pop-Busui R, Boulton AJ, Feldman EL, et al. Diabetic neuropathy: a position statement by the American diabetes association. Diabetes Care. 2017;40(1):136-154. doi:10.2337/dc16-2042

13. Axer H, Grimm A, Porzelius C, et al. Impairment of small somatic and autonomic nerve fibres in intensive care unit patients with severe sepsis and critical illness polyneuropathy-a single center controlled observational study. BMC Neurol. 2013;13:159. doi:10.1186/14712377-13-159

14. American Diabetes Association. 11. Microvascular complications and foot care: standards of medical care in diabetes-2019. Diabetes Care. 2019;42.

15. Neuroultrasound Professional Committee of neurophysician branch of Chinese Medical Association; neuroimaging collaboration group of Neurology branch of Chinese Medical Association. Operation specification of neuroultrasound in China. Natl Med J China. 2017;97(43):3361-3370.

16. Wu X, OuYang Q, Luo F, Wu S. Evaluation of asymmetric neuropathic pain with DCEC ultrasound scoring. Chin J Med Imaging. 2019;27(4):292-297.

17. Herraets IJT, Goedee HS, Telleman JA, et al. Nerve ultrasound improves detection of treatment-responsive chronic inflammatory neuropathies. Neurology. 2020;94(14):1-10. doi:10.1212/WNL.0000000000008978

18. Singh Y, Dixit R, Singh S, Garg S, Chowdhury N. High resolution ultrasonography of peripheral nerves in diabetic peripheral neuropathy. Neurol India. 2019;67:S71-S76. doi:10.4103/0028-3886.250719

19. Zhu J. Ultrasound Imaging of Peripheral Neuropathy. Beijing: People's Medical Publishing House; 2017.

20. Sztanek F, Molnárné Molnár Á, Balogh Z. The role of oxidative stress in the development of diabetic neuropathy. Orv Hetil. 2016;157(49):1939-1946. doi:10.1556/650.2016.30609

21. Emril DR, Zakaria I, Amrya M. Agreement between high-resolution ultrasound and electro-physiological examinations for diagnosis of carpal tunnel syndrome in the Indonesian population. Front Neurol. 2019;10:888. doi:10.3389/fneur.2019.00888

22. Pitarokoili K, Kerasnoudis A, Behrendt V, et al. Facing the diagnostic challenge: nerve ultrasound in diabetic patients with neuropathic symptoms. Muscle Nerve. 2016;54:18-24. doi:10.1002/mus.24981

23. Omejec G, Žgur T, Podnar S. Diagnostic accuracy of ultrasonographic and nerve conduction studies in ulnar neuropathy at the elbow. Clin Neurophysiol. 2015;126:1797-1804. doi:10.1016/j.clinph.2014.12.001

24. Omejec G, Podnar S. Utility of nerve conduction studies and ultrasonography in ulnar neuropathies at the elbow of different severity. Clin Neurophysiol. 2020;131(7):1672-1677. doi:10.1016/j.clinph.20 20.02.019 
25. Riazi S, Bril V, Perkins BA, et al. Can ultrasound of the tibial nerve detect diabetic peripheral neuropathy? A cross-sectional study. Diabetes Care. 2012;35:2575-2579. doi:10.2337/dc12-0739

26. Ishibashi F, Taniguchi M, Kojima R, Kawasaki A, Kosaka A, Uetake H. Morphological changes of the peripheral nerves evaluated by high-resolution ultrasonography are associated with the severity of diabetic neuropathy, but not corneal nerve fiber pathology in patients with type 2 diabetes. J Diabetes Investig. 2015;6(3):334-342. doi:10. 1111/jdi.12299

27. Pelosi L, Mulroy E. Diagnostic sensitivity of electrophysiology and ultrasonography in ulnar neuropathies of different severity. Clin Neurophysiol. 2019;130:297-302. doi:10.1016/j.clinph.2018.11.018

28. Pourmemari MH, Shiri R. Diabetes as a risk factor for carpal tunnel syndrome: a systematic review and meta-analysis. Diabet Med. 2016;33(1):10-16. doi:10.1111/dme.12855

29. Chen IJ, Chang KV, Lou YM, Wu WT, Özçakar L. Can ultrasound imaging be used for the diagnosis of carpal tunnel syndrome in diabetic patients? A systemic review and network meta-analysis. J Neurol. 2020;267(7):1887-1895. doi:10.1007/s00415-019-09254-8

30. Borire AA, Issar T, Kwai NC, et al. Correlation between markers of peripheral nerve function and structure in type 1 diabetes. Diabetes Metab Res Rev. 2018;34(7):e3028. doi:10.1002/dmrr.3028

31. Rockenfeller P, Ring J, Muschett V, et al. Fatty acids trigger mitochondrion-dependent necrosis. Cell Cycle. 2010;9 (14):2836-2842. doi:10.4161/cc.9.14.12346

32. Podnar S, Omejec G, Bodor M. Nerve conduction velocity and cross-sectional area in ulnar neuropathy at the elbow. Muscle Nerve. 2017;56:E65-E72. doi:10.1002/mus.25655

33. Yan A, Issar T, Tummanapalli SS, et al. Relationship between corneal confocal microscopy and markers of peripheral nerve structure and function in Type 2 diabetes. Diabet Med. 2020;37(2):326-334. doi:10.1111/dme.13952

34. Arumugam T, Razali SNO, Vethakkan SR, Rozalli FI, Shahrizaila N. Relationship between ultrasonographic nerve morphology and severity of diabetic sensorimotor polyneuropathy. Eur J Neurol. 2016;23 (2):354-360. doi:10.1111/ene.12836

35. Carandang MAE, Takamatsu N, Nodera H, et al. Velocity of intraneural blood flow is increased in inflammatory neuropathies: sonographic observation. J Neurol Neurosurg Psychiatry. 2017;88: 455-457. doi:10.1136/jnnp-2016-314547

36. Kutlar N, Bayrak AO, Bayrak İK, Canbaz S, Türker H. Diagnosing carpal tunnel syndrome with Doppler ultrasonography: a comparison of ultrasonographic measurements and electrophysiological severity. Neurol Res. 2017;39:126-132. doi:10.1080/01616412.2016.1275455

37. Karahan AY, Arslan S, Ordahan B, Bakdik S, Ekiz T. Superb microvascular imaging of the median nerve in carpal tunnel syndrome: an electrodiagnostic and ultrasonographic study. J Ultrasound Med. 2018;37:2855-2861. doi:10.1002/jum.14645

38. Olver DT, Lacefield JC, Shoemaker KJ. Evidence of bidirectional flow in the sciatic vasa nervorum. Microvasc Res. 2014;94:103-105. doi:10.1016/j.mvr.2014.05.008

39. Sun D, Wang Y. Ultrasonic features of tibial nerve in type 2 diabetes mellitus with diabetic peripheral neuropathy. Chin J Med Imaging. 2014;30(10):781-783.

40. Ma X, Du L, Lei T, Han T. Feature analysis of high-frequence ultrasound and neural eletrophysiological examination in peripheral neuropathy caused by type 2 diabetes mellitus. J China Clin Med Imaging. 2019;30(10):734-737.

41. Tan JS, Lin CC, Chen GS. Vasomodulation of peripheral blood flow by focused ultrasound potentiates improvement of diabetic neuropathy. BMJ Open Diabetes Res Care. 2020;8:undefined. doi:10.1136/bmjdrc-2019-001004

42. Lee CC, Perkins BA, Kayaniyil S, et al. Peripheral neuropathy and nerve dysfunction in individuals at high risk for type 2 diabetes: the PROMISE cohort. Diabetes Care. 2015;38(5):793-800. doi:10.2337/ dc14-2585
43. Kerasnoudis A, Tsivgoulis G. Nerve ultrasound in peripheral neuropathies: a review. J Neuroimaging. 2015;25:528-538. doi:10.1111/ jon. 12261

44. Kerasnoudis A, Pitarokoili K, Behrendt V, Gold R, Yoon MS. Nerve ultrasound score in distinguishing chronic from acute inflammatory demyelinating polyneuropathy. Clin Neurophysiol. 2014;125: 635-641. doi:10.1016/j.clinph.2013.08.014

45. Kerasnoudis A, Pitarokoili K, Behrendt V, Gold R, Yoon MS. Bochum ultrasound score versus clinical and electrophysiological parameters in distinguishing acute-onset chronic from acute inflammatory demyelinating polyneuropathy. Muscle Nerve. 2015;51: 846-852. doi:10.1002/mus.24484

46. Kerasnoudis A, Pitarokoili K, Haghikia A, Gold R, Yoon MS. Nerve ultrasound protocol in differentiating chronic immune-mediated neuropathies. Muscle Nerve. 2016;54:864-871. doi:10.1002/mus.25 138

47. Grimm A, Décard BF, Axer H, Fuhr P. The ultrasound pattern sum score - UPSS. A new method to differentiate acute and subacute neuropathies using ultrasound of the peripheral nerves. Clin Neurophysiol. 2015;126 (11):2216-2225. doi:10.1016/j.clinph.2015.01.011

48. Grimm A, Vittore D, Schubert V, et al. Ultrasound pattern sum score, homogeneity score and regional nerve enlargement index for differentiation of demyelinating inflammatory and hereditary neuropathies. Clin Neurophysiol. 2016;127(7):2618-2624. doi:10.1016/j.clinph.20 16.04 .009

49. Grimm A, Rattay TW, Winter N, Axer H. Peripheral nerve ultrasound scoring systems: benchmarking and comparative analysis. J Neurol. 2017;264:243-253. doi:10.1007/s00415-016-8305-y

50. Grimm A, Winter N, Rattay TW, et al. A look inside the nerve - morphology of nerve fascicles in healthy controls and patients with polyneuropathy. Clin Neurophysiol. 2017;128:2521-2526. doi:10.1016/j.clinph.2017.08.022

51. Breiner A, Qrimli M, Ebadi H, et al. Peripheral nerve high-resolution ultrasound in diabetes. Muscle Nerve. 2017;55(2):2-29. doi:10.1002/ mus. 25223

52. Borire AA, Visser LH, Padua L, et al. Utility of maximum perfusion intensity as an ultrasonographic marker of intraneural blood flow. Muscle Nerve. 2017a;55:77-83. doi:10.1002/mus.25200

53. Borire AA, Issar T, Kwai NC, et al. Sonographic assessment of nerve blood flow in diabetic neuropathy. Diabet Med. 2020;37(2):343-349. doi: $10.1111 /$ dme. 14085

54. Farias Zuniga A, Ghavanini AA, Israelian G, Keir PJ. Blood flow velocity but not tendon mechanics relates to nerve function in carpal tunnel syndrome patients. J Neurol Sci. 2020;411:116694. doi:10.1016/j.jns.2020.116694

55. Wang Y, Tang P, Zhang L, Guo Y, Wan W. Quantitative evaluation of the peripheral nerve blood perfusion with high frequency contrast-enhanced ultrasound. Acad Radiol. 2010;17:1492-1497. doi:10.1016/j.acra.2010.07.007

56. Watanabe $\mathrm{T}$, Ito $\mathrm{H}$, Sekine $\mathrm{A}$, et al. Sonographic evaluation of the peripheral nerve in diabetic patients: the relationship between nerve conduction studies, echo intensity, and cross-sectional area.J. Ultrasound Med. 2010;29:697-708. doi:10.7863/jum.2010.29.5.697

57. OuYang Q, Wu X, Lin Y, Tang C, Wu S. Ultrasonic diagnostic score for diabetic peripheral neuropathy. Chin J Nervous Ment Dis. 2019;45(4):197-201.

58. Adams OP, Herbert JR, Howitt C, Unwin N. The prevalence of peripheral neuropathy severe enough to cause a loss of protective sensation in a population-based sample of people with known and newly detected diabetes in Barbados: a cross-sectional study. Diabet Med. 2019;36:1629-1636. doi:10.1111/dme.13989

59. Zhen Q, Yao N, Chen X, Zhang X, Wang Z, Ge Q. Total body adiposity, triglycerides, and leg fat are independent risk factors for diabetic peripheral neuropathy in chinese patients with type 2 diabetes mellitus. Endocr Pract. 2019;25:270-278. doi:10.4158/EP2018-0459 
60. Elnady B, Rageh EM, Hussein MS, et al. In shoulder adhesive capsulitis, ultrasound-guided anterior hydrodilatation in rotator interval is more effective than posterior approach: a randomized controlled study. Clin Rheumatol. 2020.

61. Paluch Ł, Noszczyk BH, Walecki J, Osiak K, Kiciński M, Pietruski P. Shear-wave elastography in the diagnosis of ulnar tunnel syndrome. J Plast Reconstr Aesthet Surg. 2018;71:1593-1599. doi:10.1016/j. bjps.2018.08.018

62. Wee TC, Simon NG. Ultrasound elastography for the evaluation of peripheral nerves: a systematic review. Muscle Nerve. 2019;60:501-512. doi:10.1002/mus.26624

63. Anno S, Okano T, Mamoto K, et al. Comparison of median nerve stiffness with and without rheumatoid arthritis by ultrasound real-time tissue elastography: a propensity score matching study. Modern Rheumatol. 2020;30 (3):481-488. doi:10.1080/14397595.2019.1602914

64. Nogueira-Barbosa MH, Lugão HB, Gregio-Júnior E, et al. Ultrasound elastography assessment of the median nerve in leprosy patients. Muscle Nerve. 2017;56:393-398. doi:10.1002/mus.25510

65. Dikici AS, Ustabasioglu FE, Delil S, et al. Evaluation of the tibial nerve with shear-wave elastography: a potential sonographic method for the diagnosis of diabetic peripheral neuropathy. Radiology. 2017;282(2):494-501. doi:10.1148/radiol.2016160135

66. Ishibashi F, Taniguchi M, Kojima R, Kawasaki A, Kosaka A, Uetake H. Elasticity of the tibial nerve assessed by sonoelastography was reduced before the development of neuropathy and further deterioration associated with the severity of neuropathy in patients with type 2 diabetes. J Diabetes Investig. 2015;7(3):404-412. doi:10.1111/ jdi. 12408

67. Jiang W, Huang S, Teng $\mathrm{H}$, et al. Diagnostic performance of two-dimensional shear wave elastography for evaluating tibial nerve stiffness in patients with diabetic peripheral neuropathy. Eur Radiol. 2019;29(5):2167-2174. doi:10.1007/s00330-018-5858-4

68. Chen R, Wang XL, Xue WL, et al. Application value of conventional ultrasound and real-time shear wave elastography in patients with type 2 diabetic polyneuropathy. Eur J Radiol. 2020;126:108965. doi:10.1016/j.ejrad.2020.108965

69. Wilder J, Choi SS, Moylan CA. Vibration-controlled transient elastography for diagnosing cirrhosis and staging hepatic fibrosis. JAMA Diagnostic Test Interpret. 2018;320(19):E1-E2.

70. Aughsteen AA, Khair AM, Suleiman AA. Quantitative morphometric study of the skeletal muscles of normal and streptozotocin-diabetic rats. JOP. 2006;7:382-389.
71. Chiu CY, Yang RS, Sheu ML, et al. Advanced glycation end-products induce skeletal muscle atrophy and dysfunction in diabetic mice via a RAGE-mediated, AMPK-down-regulated, Akt pathway. J Pathol. 2016;238:470-482. doi:10.1002/path.4674

72. Andreassen CS, Jakobsen J, Ringgaard S, Ejskjaer N, Andersen H. Accelerated atrophy of lower leg and foot muscles-a follow-up study of long-term diabetic polyneuropathy using magnetic resonance imaging (MRI). Diabetologia. 2009;52:1182-1191. doi:10.1007/s00125009-1320-0

73. Andersen H. Motor function in diabetic neuropathy. Acta Neurol Scand. 1999;100:211-220. doi:10.1111/j.1600-0404.1999.tb00383.x

74. Andersen H. Motor dysfunction in diabetes. Diabetes Metab Res Rev. 2012;28:89-92. doi:10.1002/dmrr.2257

75. Pham M, Oikonomou D, Bäumer P, et al. Proximal neuropathic lesions in distal symmetric diabetic polyneuropathy: findings of high-resolution magnetic resonance neurography. Diabetes Care. 2011;34:721-723. doi:10.2337/dc10-1491

76. Hlis R, Poh F, Bryarly M, Xi Y, Chhabra A. Quantitative assessment of diabetic amyotrophy using magnetic resonance neurography - a case-control analysis. Eur Radiol. 2019;29(11):5910-5919. doi:10.1007/s00330-019-06162-3

77. Pillen S, Boon A, Van Alfen N. Muscle ultrasound. Handb Clin Neurol. 2016;136:843-853.

78. Severinsen K, Obel A, Jakobsen J, Andersen H. Evaluation of atrophy of foot muscles in diabetic neuropathy - a comparative study of nerve conduction studies and ultrasonography. Clin Neurophysiol. 2007;118:2172-2175. doi:10.1016/j.clinph.2007.06.019

79. De Souza Silva CR, Dos Santos Costa A, Rocha T, et al. Quadriceps muscle architecture ultrasonography of individuals with type 2 diabetes: reliability and applicability. PLoS One. 2018;13(10):1-9.

80. Ono Y, Esaki K, Takahashi Y, Nakabayashi M, Ichinose M, Lee K. Muscular blood flow responses as an early predictor of the severity of diabetic neuropathy at a later stage in streptozotocin-induced type I diabetic rats: a diffuse correlation spectroscopy study. Biomed Opt Express. 2018;9:4539-4551. doi:10.1364/BOE.9.004539

81. Georgiev GP, Karabinov V, Kotov G, Iliev A. Medical ultrasound in the evaluation of the carpal tunnel: a critical review. Cureus. 2018;10: e3487.

\section{Publish your work in this journal}

Diabetes, Metabolic Syndrome and Obesity: Targets and Therapy is an international, peer-reviewed open-access journal committed to the rapid publication of the latest laboratory and clinical findings in the fields of diabetes, metabolic syndrome and obesity research. Original research, review, case reports, hypothesis formation, expert opinion and commentaries are all considered for publication. The manuscript management system is completely online and includes a very quick and fair peer-review system, which is all easy to use. Visit http://www.dovepress.com/testimonials.php to read real quotes from published authors. 